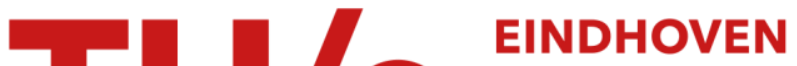 \\ UNIVERSITY OF \\ TECHNOLOGY
}

\section{Stated preference and choice models applied to recreation research : a review}

Citation for published version (APA):

Louviere, J. J., \& Timmermans, H. J. P. (1990). Stated preference and choice models applied to recreation research : a review. Leisure Sciences, 12(1), 9-32.

Document status and date:

Published: 01/01/1990

\section{Document Version:}

Publisher's PDF, also known as Version of Record (includes final page, issue and volume numbers)

\section{Please check the document version of this publication:}

- A submitted manuscript is the version of the article upon submission and before peer-review. There can be important differences between the submitted version and the official published version of record. People interested in the research are advised to contact the author for the final version of the publication, or visit the $\mathrm{DOI}$ to the publisher's website.

- The final author version and the galley proof are versions of the publication after peer review.

- The final published version features the final layout of the paper including the volume, issue and page numbers.

Link to publication

\section{General rights}

Copyright and moral rights for the publications made accessible in the public portal are retained by the authors and/or other copyright owners and it is a condition of accessing publications that users recognise and abide by the legal requirements associated with these rights.

- Users may download and print one copy of any publication from the public portal for the purpose of private study or research.

- You may not further distribute the material or use it for any profit-making activity or commercial gain

- You may freely distribute the URL identifying the publication in the public portal.

If the publication is distributed under the terms of Article $25 \mathrm{fa}$ of the Dutch Copyright Act, indicated by the "Taverne" license above, please follow below link for the End User Agreement:

www.tue.nl/taverne

Take down policy

If you believe that this document breaches copyright please contact us at:

openaccess@tue.nl

providing details and we will investigate your claim. 


\title{
Stated Preference and Choice Models Applied to Recreation Research: A Review
}

\author{
JORDAN LOUVIÈRE \\ Marketing and Economic Analysis \\ University of Alberta \\ Edmonton, Canada
}

\section{HARRY TIMMERMANS}

\author{
Urban Planning \\ University of Technology \\ Eindhoven, The Netherlands
}

\begin{abstract}
This article discusses the use and usefulness of stated preference and choice models in recreation/leisure research. Stated preference and choice models require one to design decision experiments to study recreational and leisure decisions made in hypothetical or simulated markets. Historically, such experiments were uncommon in recreation and leisure research; therefore we pay particular attention to comparisons of the stated preference modeling approaches with modeling approaches based on observations of choices made in real markets, such as the analysis of discrete choices using conditional and nested multinomial logit models. The conceptual and theoretical bases of stated preference and choice models are discussed; and procedures for developing such models, including different design strategies, are outlined. Potential uses of these models in recreation research are illustrated with reference to several recent empirical applications.
\end{abstract}

\section{Introduction}

The spatial choices of recreationists play a significant role in determining the demand for and usage of recreational facilities. Consequently, leisure scientists have long been interested in understanding how individuals make choices among competing recreational opportunities. Two general modeling approaches have been developed during the past 10 to 15 years to explain and predict such choices: (1) Random utility theory in psychology and economics is used to formulate stochastic choice models that allow researchers to explain individual choices observed in real environments if the choice observations satisfy a number of assumptions. This "revealed preference" approach explains observed choice patterns in terms of an underlying utility function that is specified in terms of sets of physical measures of the attributes of choice options. Individuals reveal their utilities through the choices they make on particular visitations to recreational opportunities. If assumptions about the stochastic component of utility are satisfied, if all of the appropriate attributes that influence choice have been specified, if the appropriate form of the utility function and the choice process have been applied, then one can test statistical 
hypotheses about the attributes and make forecasts concerning changes in choices that will result from changes in policies reflected in the attribute levels.

(2) A second paradigm relies on observations made by real decisionmakers in carefully designed, hypothetical markets. Because it relies on individual's statements about their preferences or choices, this approach has become known as "stated preference" (or choice) analysis. Although revealed and stated approaches share a common body of theory, there are important differences in data collection, assumptions, and statistical methods used to develop and test models (Table 1). In this article we distinguish between "stated preference" and "stated choice" methods. Stated preference analysis relies on one-at-atime stated judgments (or opinions) of options that systematically vary on attribute dimensions, and includes paradigms like information integration and conjoint analysis. Such stated preference paradigms belong to a family of theory and methods that are used to estimate preference or utility functions that measure preferences or utilities and describe how individuals combine their preferences for the levels of the attributes of choice options to form an overall opinion of or preference for particular options. In contrast, stated choice analysis, like revealed choice analysis, is based on random utility theory, and includes a family of theory and methods that can be applied to measure preferences, and specify and test choice models based on data obtained in discrete choice experiments. Individuals make choices among hypothetical or altered real choice alternatives, and these stated choices are used to estimate the parameters of preference or utility functions associated with various stochastic choice processes. Thus, stated choice experiments involve comparisons of competing choice alternatives while preference experiments do not. Nonetheless, unless specifically indicated, our discussion refers to both types of experiments.

Stynes and Peterson (1986) recently reviewed applications of discrete choice models in recreation; consequently, we avoid repeating such a review. Rather, our purpose is to (1) review the stated preference/choice paradigm, (2) describe several ways in which stated preference/choice models can be used to explain and forecast recreational choices, and (3) discuss how such models can be used to evaluate alternative investments and policies. We hope to demonstrate that stated preference/choice models represent a valuable approach to the study of recreational demand forecasting and a valuation of policy alternatives. Indeed, for many applications, stated preference/choice analysis is an inexpensive alternative to revealed preference analysis and can be especially valuable in situations in which one wishes to assess the consequences of introducing new or repositioning current alternatives that will have one or more attributes not present in, or attribute levels that differ markedly (either in range or magnitude) from existing alternatives. Likewise, stated preference/choice analysis can be useful when one wishes to evaluate technologically new or otherwise radically different recreation or management concepts.

To accomplish these objectives, we organized the article as follows: First we briefly discuss theory and methods of design and analysis associated with multiattribute stated preference and choice models, followed by a description of how such models can be applied, including various steps in the model-building process. Then we discuss alternative strategies for designing stated preference and choice experiments. Next we describe how the theory and methods can be used to analyze various problems of interest to recreation managers and policymakers, including several illustrative applications. The article concludes with a discussion of advantages and limitations of stated preference and choice models vis-á-vis revealed choice models. 
Table 1

Differences Between Stated Preference and Choice Modeling

\begin{tabular}{|c|c|c|}
\hline & Preference Modeling & Choice Modeling \\
\hline Data collection & Experimental setting & Experimental setting \\
\hline Profiles/stimuli & $\begin{array}{l}\text { Descriptions of } \\
\text { individual choice } \\
\text { alternatives }\end{array}$ & $\begin{array}{l}\text { Descriptions of choice sets } \\
\text { consisting of profiles or } \\
\text { (real-world) choice } \\
\text { alternative }\end{array}$ \\
\hline Respondent task & $\begin{array}{l}\text { Rate or rank sets of } \\
\text { attribute profiles }\end{array}$ & $\begin{array}{l}\text { Choose one option from a } \\
\text { set including a no } \\
\text { choice option or allocate } \\
\text { resources }\end{array}$ \\
\hline Task complexity & Relatively difficult & Relatively easy \\
\hline Dependent variable & Rankings or rating & $\begin{array}{l}\text { Discrete choices or choice } \\
\text { frequencies }\end{array}$ \\
\hline Estimation methods & $\begin{array}{l}\text { Ranking data: } \\
\text { Nonmetric scaling; } \\
\text { linear } \\
\text { programming } \\
\text { Rating data: OLS } \\
\text { regression analysis }\end{array}$ & $\begin{array}{l}\text { Multinomial Logit Analysis } \\
\text { using } \\
\text { Maximum likelihood } \\
\text { Generalized least squares }\end{array}$ \\
\hline Output & $\begin{array}{l}\text { Utility function } \\
\text { Prediction of choices } \\
\text { and market shares } \\
\text { if choice simulator } \\
\text { is used }\end{array}$ & $\begin{array}{l}\text { Prediction of choices and } \\
\text { market shares }\end{array}$ \\
\hline Aspects of validity & $\begin{array}{l}\text { Normally rate } \\
\text { profiles } \\
\text { one-at-a-time } \\
\text { Choices not examined } \\
\text { directly } \\
\text { Choice rules ad hoc }\end{array}$ & $\begin{array}{l}\text { Forced to make } \\
\text { comparisons } \\
\text { Choices are observed }\end{array}$ \\
\hline Heterogeneity & $\begin{array}{l}\text { Individual-level } \\
\text { models can be } \\
\text { constructed }\end{array}$ & $\begin{array}{l}\text { Difficult to develop } \\
\text { individual-level choice } \\
\text { models. }\end{array}$ \\
\hline Flexibility & $\begin{array}{l}\text { Wide with respect to } \\
\text { level of } \\
\text { aggregation, } \\
\text { selection of } \\
\text { attributes and } \\
\text { specification of } \\
\text { choice simulator }\end{array}$ & $\begin{array}{l}\text { Little, as many operational } \\
\text { decisions are dictated by } \\
\text { aggregate nature of the } \\
\text { approach and estimable } \\
\text { choice models }\end{array}$ \\
\hline $\begin{array}{l}\text { Ease of } \\
\text { implementation }\end{array}$ & $\begin{array}{l}\text { Easy for small scale } \\
\text { problems }\end{array}$ & More difficult \\
\hline
\end{tabular}




\section{Theory and Practice of Stated Preference and Choice Modeling}

Stated preference and choice models owe their current popularity to three sources: (1) dissatisfaction with the degree of explanatory and predictive performance of aggregate econometric and related statistical models that were applied to many demand and policy evaluation problems in transportation, urban planning, geography, regional economics, and recreation from 1965 to 1980 , (2) the development of theory and methods of analysis in behavioral decision theory in psychology and utility theory in economics, and (3) significant advances in the design of statistical experiments that permit one to study individual and aggregate decisions under rigorously controlled conditions. The latter advances were particularly important because, for the first time, one could estimate and test utility functions without the typical limitations imposed by real markets: e.g., limited range or variance in explanatory variables, statistical confoundment because of intervariable correlations and effects because of omitted and unobserved variables.

It is well known, but unfortunately little appreciated, that unless real choice data satisfy the assumptions required of statistical choice models, the estimates of the utilities (or statistical effects) are likely to be biased by the aforementioned problems with observations made in real markets. This bias can be substantial, and rarely can be anticipated or ameliorated without knowledge rarely available to an analyst. Such bias problems are common in observational data sets because one has no control over the nature and composition of either choice alternatives or the characteristics of those who choose among them in real settings. Moreover, revealed preference/behavior models cannot predict radical changes in environmental systems or choice processes because the variables and processes involved in such changes are typically unobserved. Similarly, such models cannot be used to predict the likely effects of new choice alternatives that differ from present experience because revealed data contain no information about their effects on existing alternatives. More important, recreational opportunities often vary in terms of context or environmental variables that appear constant within study regions, but often show considerable differences between study regions. Because large-scale cross-sectional and longitudinal research is expensive and time consuming, one rarely sees such (empirically unobserved) differences taken into account in revealed choice models.

The stated preference/choice paradigms discussed in this article assume individuals use some process rule or utility function to integrate information about variables that describe and differentiate choice alternatives. The variables that describe choice alternatives are termed the attributes of these alternatives, and the values of these attributes over which real alternatives range are termed their levels. We assume that individuals form impressions or beliefs about various salient attributes of real alternatives; however, because of limitations in human information processing capabilities, time and resource constraints, or differences in personal tastes and preferences, individuals may not consider all available choice alternatives, or use all possible attributes to evaluate alternatives.

Rather, individuals choose subsets of attributes and alternatives to consider and evaluate. As individuals form impressions about recreation alternatives, they make value judgments: Is it better for a park to be heavily forested or to have areas of trees interspersed with grassy meadows; is it better for a national forest to have no off-road access to motorized vehicles or to allow limited access to All Terrain Vehicles (ATVs) and horses? Once they form such value judgments, individuals integrate these values or utilities into an overall impression (overall utility of) a park or forest. On the basis of the relative levels of utility offered by various options, we assume that individuals then form choice sets from which they decide which alternative, if any, to choose for a particular 
type of recreational activity at a particular moment in time. Consistent with random utility theory, we further assume that choices are the outcome of a utility maximization process in which individuals try to choose the best option for their circumstances. Such choices are stochastic from the analyst's viewpoint because a large number of events can influence choice aside from the attributes of the choice options; therefore, even if choice options remain constant, individuals can be observed to vary in their choices from observation to observation.

The notion of information integration is essential to the conceptual framework: The preferences or choices stated by individuals reveal their attribute values or utilities; hence, the functional form of an individual's or group's utility function can be diagnosed or tested by designing an appropriate experiment and performing certain statistical analyses on the stated preference data. Thus, the assumption of information integration and of stated responses revealing individuals' utilities constitute key axioms in stated preference or choice modeling (Timmermans 1984a; Louviére 1988).

\section{Stated Preference and Choice Models}

As implied by the previous discussion, the construction of a stated preference or choice model involves the following steps/decisions, which we discuss in detail here:

(1) Identification of salient attributes for particular decision-making or choice contexts.

(2) Specification of attribute levels for particular decision-making or choice contexts.

(3) Selection of an appropriate method for combining attribute levels into descriptions of choice alternatives.

(4) Choice of an experimental design to place the choice alternatives into sets in which stated preference or choice responses are observed.

(5) Choice of a "good" (meaning realistic and within the limits of human processing capabilities) way to present the choice alternatives to individuals so that one can observe their stated preferences or choices.

(6) Choice of a procedure to measure individuals' stated preferences or choices for a particular problem context.

(7) Choice of method for estimating utility function(s).

(8) Choice of an approach to map utilities into overt choices.

Let us consider each of these steps in turn.

\section{Identification of Salient Attributes}

Methods such as in-depth interviews, repertory grids, focus group interviews, direct questioning, protocols, and such are used to identify salient attributes that influence choices. All individuals are idiosyncratic in their choice behavior to some extent, therefore one must decide whether to use individual-specific attributes or attributes that are salient to most individuals most of of the time. To identify the most salient attributes one typically considers the following criteria: (1) Is it necessary to include an exhaustive list of al salient attributes (can one ignore attributes that are largely idiosyncratically salient without significant bias)? (2) Which attributes can be retained, recombined, or reexpressed to keep the set of attributes as nonredundant and as few as possible to make an experiment tractible? (3) In planning or policy applications can one include nonsalient attributes that are actionable and interesting to managers? (4) Does one need to specify 
relationships between subjective attributes such as "convenience," "quality wilderness experience," or "crowding" and objective, actionable antecedents, like whether cars are barred, the number of back country permits issued, etc.?

\section{Specification of Attribute Levels}

Specification of attribute levels is dictated by one's research objectives. For example, attribute levels often are chosen so that they span the range observed in current or planning horizon choice alternatives. Other times, the range of attributes is fixed by certain constraints, such as the physical nature of facilities or law. Of course one can specify attribute levels that are beyond the domain of current or past experience, but one should be cautious about the way in which this is accomplished because it can affect the reliability of the responses and the meaningfulness of one's results, especially if individuals find them unbelievable.

\section{Combining Attribute Levels (Choice of Experimental Design)}

Statistical design theory utilized to develop statistical experiments is used to combine the levels of the various attributes into scenarios or descriptions of different choice alternatives (Veldhuisen and Timmermans 1984; Louvière 1988). Each combination of attribute levels is termed a "treatment" in the design literature or a "profile" in the conjoint analysis literature. Profiles are descriptions of separate choice alternatives, such as parks described by their terrain, vegetation density, water features, facilities, and activities. Each variable is an attribute that can take on several levels. For example, levels of terrain might be pictures or verbal descriptions of different terrain possibilities such as "flat and prairielike" to "rugged and mountainous with many peaks and ridges"; levels of facilities like picnic tables might be "yes/no," or levels of activities like fishing might be "none, restricted to artificial lures only, open to all types of fishing."

Profiles are generated by applying statistical design theory to create experimental designs. Each attribute represents a factor in a statistical experiment, and each factor has levels that represent the range of values of the attribute that are of interest. Factorial designs allow one to create descriptions of choice alternatives in such a way that all of the statistical effects of the attributes that are varied can be estimated independently. In practice, however, complete factorial designs are rarely used because the number of possible combinations would be impractically large; instead, fractional factorial designs are used to construct profiles. Unfortunately, to use fractional designs one must assume that certain interaction effects among the attributes are not statistically significant. If this assumption is incorrect, the resulting utility estimates will be biased because one has omitted significant variables from the analysis.

Generally, once one chooses a fraction, the ability to detect unobserved, but significant interaction effects is lost, and one cannot determine whether the estimated effects are biased. This is especially problematic for so-called main effects plans, which permit one to estimate only the additive, main effects of the attributes. To use main effects designs correctly, it must be the case that individuals process attribute information in a strictly additive manner, which implies that the effects of each attribute on the stated responses is independent of the effects of the remaining attributes. Previous research has often demonstrated that this assumption is rarely correct; as a result one 
should use fractional factorial designs that allow one to estimate all main effects plus as many interaction effects as possible. At a minimum, one should use fractions that allow one to estimate nonlinear main effects and as many two-way interactions as possible.

Experiments in which individuals make discrete choices among competing options are called stated choice tasks. Experiments that involve observations of ranking sets of alternatives, or judging each alternative in a set on a category rating scale are called ranking or rating tasks. The design and analysis of choice tasks is more complex than the design of rating and ranking tasks because the latter are based on design theory associated with the estimation of general linear models, whereas the former are based on design theory for the estimation of discrete multivariate, nonlinear models.

In particular, the creation of a task in which subjects choose among multiattribute alternatives requires one to design (1) attribute profiles that represent hypothetical choice alternatives, and (2) "choice sets" into which to place the profiles generated by the first design. Choice sets contain descriptions of two or more competing alternatives from which individuals make only a single (discrete) choice. Choice sets cannot be designed arbitrarily because different statistical choice models (e.g., the multinomial logit (MNL) model) require satisfaction of different statistical assumptions to insure consistent and efficient parameter estimates. For example, certain types of fractional factorial designs can be used to construct both the alternatives and the choice sets in which they are placed thereby satisfying the assumptions underlying the MNL model (Louvière and Woodworth 1983).

\section{Presentation of Choice Alternatives}

Sentences, short phrases, or paragraphs; pictures, drawings, photographs, or CAD/ CAM representations; models or mockups; or any combinations of these may be used to describe hypothetical choice alternatives produced by combining attribute levels. Also one can use real choice objects, real ad copy, real ingredients, or any other real physical representations to describe attribute levels and alternatives.

\section{Measurement of Preferences or Choices}

In a stated preference experiment one is interested in the way in which stated strength of preference varies as attribute levels vary. Previously, it was common to ask individuals to rank profiles in applied problems; however, Cattin and Wittink $(1982,1986)$ report ranking of profiles is now rare. Instead, evaluating profiles on category rating scales has become the dominant response format used by academics and practitioners. For this reason we ignore further discussion of ranking tasks in this article. Rating tasks require individuals to express their strength of preference for each choice alternative on some category rating scale, e.g., a 0 (very low preference) to 10 (very high preference) numerical scale.

In choice experiments individuals make discrete choices among sets of profiles or choice objects (which can include existing options), or they allocate a fixed set of resources (time, trips, money, etc.) to the competing choice alternatives to represent how they would be likely to distribute these resources over some longitudinal observation period (e.g., three months). 


\section{Estimation Procedures}

Estimation procedures depend on the type of data generated by the task (e.g., rating versus choice), the specification of the utility function, and the specification of the choice process. Commonly, if one observes ratings on a category scale, OLS regression techniques are used to estimate the parameters of particular utility specifications from the ratings data conditional on the design matrix of attribute levels. In the case of discrete choice or resource allocation tasks, maximum likelihood or similar techniques are commonly used to estimate the parameters of particular utility specifications conditional on an attribute/alternative design matrix and an assumed form of the choice process. Details of commonly used estimation procedures can be found in Louvière (1988) and Veldhuisen and Timmermans (1984).

In the case of OLS estimation applied to stated preference ratings, dummy or effects coding is frequently used to represent the attribute levels in the design matrix. If 1,0 dummy coding is used, the intercept of the regression equation equals the utility of an alternative that is described by the zero-th level on all attributes; and the regression coefficients represent the incremental part-worth utilities of the other attribute levels. If one uses effects coding, all coefficients represent contrasts (differences) between the utility of the corresponding attribute level and the overall mean utility.

In a choice experiment the dependent variable is a discrete realization of the fact that one alternative was chosen (normally coded 1), whereas the remaining alternatives (coded 0) were not. Typically, one cannot estimate discrete choice models for single individuals because there are too few observations to satisfy the asymptotic conditions needed to obtain consistent and efficient parameter estimates. Satisfaction of the asymptotic properties ordinarily requires large numbers of observations of discrete choices (e.g., 10 to 20 times the number of observations obtained from individuals in choice tasks). Consequently, one normally aggregates individuals' $(1,0)$ discrete responses into choice frequencies, which represent choice outcomes for the entire sample or particular segments of interest. Alternatively, one can treat resource allocation responses "as if" they are frequency counts.

Maximum likelihood or related estimation procedures (e.g., iteratively reweighted least-squares) are commonly applied to estimate the parameters of particular utility functions given assumptions about the choice process. Other estimation procedures that have been proposed and applied include the following: (1) generalized least-squares (GLS) estimation applied to the natural $\log$ of the observed odds ratios (Theil 1979), (2) weighted least squares estimation applied to the natural log of the choice frequencies (Nakanishi and Cooper 1974, 1982; Louvière and Woodworth 1983). One GLS estimation procedure that converges to the maximum likelihood solution is iteratively reweighted least squares (Woodworth and Louvière 1985). Louvière and Timmermans (1987) discuss these techniques in greater detail; however, Bunch and Batsell (1989) have recently demonstrated the consistent superiority of maximum likelihood for cases in which the choice outcomes can be well-approximated by specifications from the family of conditional logit models.

\section{Preference-Choice Link}

If one wishes to use the results of a stated preference experiment to predict choice behavior, one must transform predicted utility values into choices. A common approach 
to this problem is to develop a computerized choice simulator, which entails the following: (1) One describes the choice alternatives of interest in terms of the attribute levels varied in the experiment; (2) OLS is used to estimate a separate utility function for each individual from their observed ratings data; (3) the OLS estimates are used to predict the overall utility of each choice alternative described in (1) for a particular individual; (4) the predicted overall utilities are mapped into predicted choices by some ad hoc rule. Often, deterministic rules are used for the mapping, such as assuming that the choice alternative with the highest predicted overall utility will be chosen. Less commonly, probabilistic mappings are used. Whatever the mapping, its validity cannot be tested statistically. In either approach, the predicted choices for each alternative are summed, and the market share of each alternative is calculated by dividing its total predicted choices by the total number of individuals. Timmermans and van der Heijden (1984) and Louvière (1988) review different possibilities. In the case of discrete choice tasks, the prediction of choice is straightforward and not ad hoc: The estimated parameters of a particular choice model are used to predict the choice probabilities (market shares) of each competing alternative.

\section{Design Strategies}

\section{Stated Preference (Ratings) Experiments}

A primary concern of a stated preference experiment is to estimate and test various specifications of the utility function to determine the one that most closely approximates the process that individuals use to integrate attribute information and form preferences for alternatives. As suggested by Louvière (1988), multilinear utility functions represent fairly general specifications that can handle both nonlinearities and nonadditivities (interactions) in a utility surface. Once a set of attributes and their associated levels is determined, it is common practice to use orthogonal, main-effects, fractional factorial designs to produce the smallest possible number of profiles necessary to estimate the parameters of a strictly additive utility function. Unfortunately, this class of designs does not permit nonadditivities to be estimated, although one can estimate nonlinear main effects if the attributes have at least three levels. Unfortunately, parameters estimated from such designs are very susceptible to bias because of unobserved and significant interaction effects that are (often perfectly) correlated with the main effects.

A better approach is to use foldover designs (e.g., see Table 2), which have the property that all linear main effects are orthogonal to unobserved but significant linearby-linear, two-factor interactions (but not all other higher order interactions). Thus, one can estimate unbiased main effects if all unobserved effects other than linear-by-linear two-way interactions are zero. This protection from bias comes at a price because foldover designs require responses to twice as many profiles, which may increase the complexity and expense of the data collection effort and possibly reduce the reliability of individuals' responses as well.

If some attributes interact, one must use design strategies that permit estimates of main effects and (at least) selected interactions. One should select designs that allow the estimation of nonlinear main effects (for attributes with three or more levels) and selected interactions, assuming that all unobserved interaction effects equal zero. One possible approach is called a compromise design. Such designs consist of a main effects plan that permits estimates of nonlinear main effects, combined with a second design that 
Table 2

Example of a Foldover Design (Replace 0's with 1's in foldover)

\begin{tabular}{|c|c|c|c|c|c|c|c|c|}
\hline \multirow[b]{2}{*}{ Profile } & \multicolumn{4}{|c|}{ Main Effects Plan } & \multicolumn{4}{|c|}{ Foldover } \\
\hline & $\begin{array}{c}\text { Attraction } \\
1\end{array}$ & $\begin{array}{c}\text { Attraction } \\
2\end{array}$ & $\begin{array}{c}\text { Attraction } \\
3\end{array}$ & $\begin{array}{c}\text { Attraction } \\
4\end{array}$ & $\begin{array}{c}\text { Attraction } \\
1\end{array}$ & $\begin{array}{c}\text { Attraction } \\
2\end{array}$ & $\begin{array}{c}\text { Attraction } \\
3\end{array}$ & $\begin{array}{c}\text { Attraction } \\
4\end{array}$ \\
\hline 1 & 0 & 0 & 0 & 0 & 1 & 1 & 1 & 1 \\
\hline 2 & 0 & 0 & 1 & 0 & 1 & 1 & 0 & 1 \\
\hline 3 & 0 & 1 & 0 & 1 & 1 & 0 & 1 & 0 \\
\hline 4 & 0 & 1 & 1 & 1 & 1 & 0 & 0 & 0 \\
\hline 5 & 1 & 0 & 0 & 1 & 0 & 1 & 1 & 0 \\
\hline 6 & 1 & 0 & 1 & 1 & 0 & 1 & 0 & 0 \\
\hline 7 & 1 & 1 & 0 & 0 & 0 & 0 & 1 & 1 \\
\hline 8 & 1 & 1 & 1 & 0 & 0 & 0 & 0 & 1 \\
\hline
\end{tabular}

permits estimates of a number of linear-by-linear interaction effects. Compromise designs usually are not orthogonal, but are fairly efficient statistically. Furthermore, bias in estimates of the main effects caused by unobserved interactions can be reduced because of the well-known property of general linear models that most of the variance in significant interactions is concentrated in the linear-by-linear interaction terms. Therefore, estimating the linear-by-linear interaction effects can reduce the bias in the main effects and provide important clues to the presence of interaction effects that can be investigated in follow-up research.

In any event, there are many design strategies available to estimate and test stated preference models. However, even if one makes use of fractional designs, one may still require an unacceptably large number of profiles to be observed. Thus, experimental tasks may still be demanding, especially if the number of attributes, the number of attribute levels, or both, are large. In such cases, there are other methods that one might consider to design stated preference experiments. For example, one approach based on the theory of Hierarchical Information Integration (HII) (Louvière 1984a) assumes that individuals use multistage decision strategies to process information in complex decision tasks. In particular, according to HII theory, individuals first categorize attributes of alternatives into a set of composite decision constructs. Examples of such constructs include "quality," "scenic beauty," or "convenience." Individuals form impressions of alternatives on these composite decision constructs and place values on the levels of these constructs. Individuals choose among the alternatives based on the values that they place on the levels of the composite decision constructs. In order to study and model this type of decision process, one must develop separate designs to study how individuals use attribute information to form impressions about each decision construct, and how variations in the levels of the decision constructs influence their choices. Louvière and Gaeth (1987) apply this approach to study preferences among supermarkets, and Timmermans (1988b) extends the approach to choice tasks. 


\section{Choice Experiments}

The design of choice experiments is much more complicated than the design of preference experiments because one has to decide simultaneously on specifications for the utility function and the choice model. Thus, choice experiments usually involve both a design to generate multiattribute profiles that describe choice options, and a design to place the profiles into choice sets. Similar to the strategy in the design of stated preference ratings experiments, one constructs the profiles in choice experiments to estimate main and as many attribute interactions effects as possible. One then combines the profiles into choice sets in such a way that one can estimate the parameters of desired utility specifications for a particular choice model (e.g., an MNL model) in a statistically consistent and efficient manner. We briefly describe some possible design strategies for choice tasks here (see summary in Table 3).

Case 1: IIA Is Satisfied, and the Utility Function Is Generic. The IIA (Independence of Irrelevant Alternatives) property of MNL and related choice models (e.g., Luce 1959) requires the utility of a particular choice alternative to be independent of the presence of other alternatives in a choice set. Thus, if alternatives A and B are in several choice sets, the odds (ratio of the choice probability of A to B) of choosing A over B must be the same in each set regardless of what other alternatives are present. IIA is also called the constant cross-elasticity property because changes in choice probabilities of other alternatives are proportional to shifts in the utility of a particular alternative. There is considerable experimental evidence that IIA is not satisfied in many real situations, but even if false, the violations may be sufficiently small to alow acceptable predictions.

Thus, if one can assume that IIA is satisfied and the parameters of the utility function are the same for all choice alternatives (i.e., the utility function is generic), there are some straightforward ways to design choice experiments that satisfy the statistical properties of the MNL choice model: (1) Design a set of profile descriptions to satisfy one's statistical requirements for estimating the utility function (i.e., specify the main and interaction effects of interest) and (2) construct a second design to place these profiles into choice sets. Basically, one has to decide on the size of the choice sets (paired or multiple comparisons) and the manner by which profiles will be assigned to choice sets (all pairs, all combinations, randomization).

First let us consider some possible choice designs for pairs of competing alternatives. Although often used in naive psychology experiments, choice experiments based on all possible pairs usually produce far too many choice sets to be practical in field settings. Furthermore, as demonstrated by Louvière and Woodworth (1983), paired comparisons designs are statistically inefficient vehicles for estimating the parameters of MNL models, although they satisfy the necessary conditions that attribute difference vectors should be orthogonal. Another method for constructing paired comparisons designs that generates many fewer pairs is to (1) construct a fractional factorial design, and (2) pair each profile in that design with its foldover. This means that each profile in a fraction competes with its mirror image. This design has the property that attribute differences are orthogonal if all attributes have two levels. The advantage of this strategy is that more profiles can be observed with fewer choice sets. If attributes have more than two levels, however, this may not be good design strategy. 


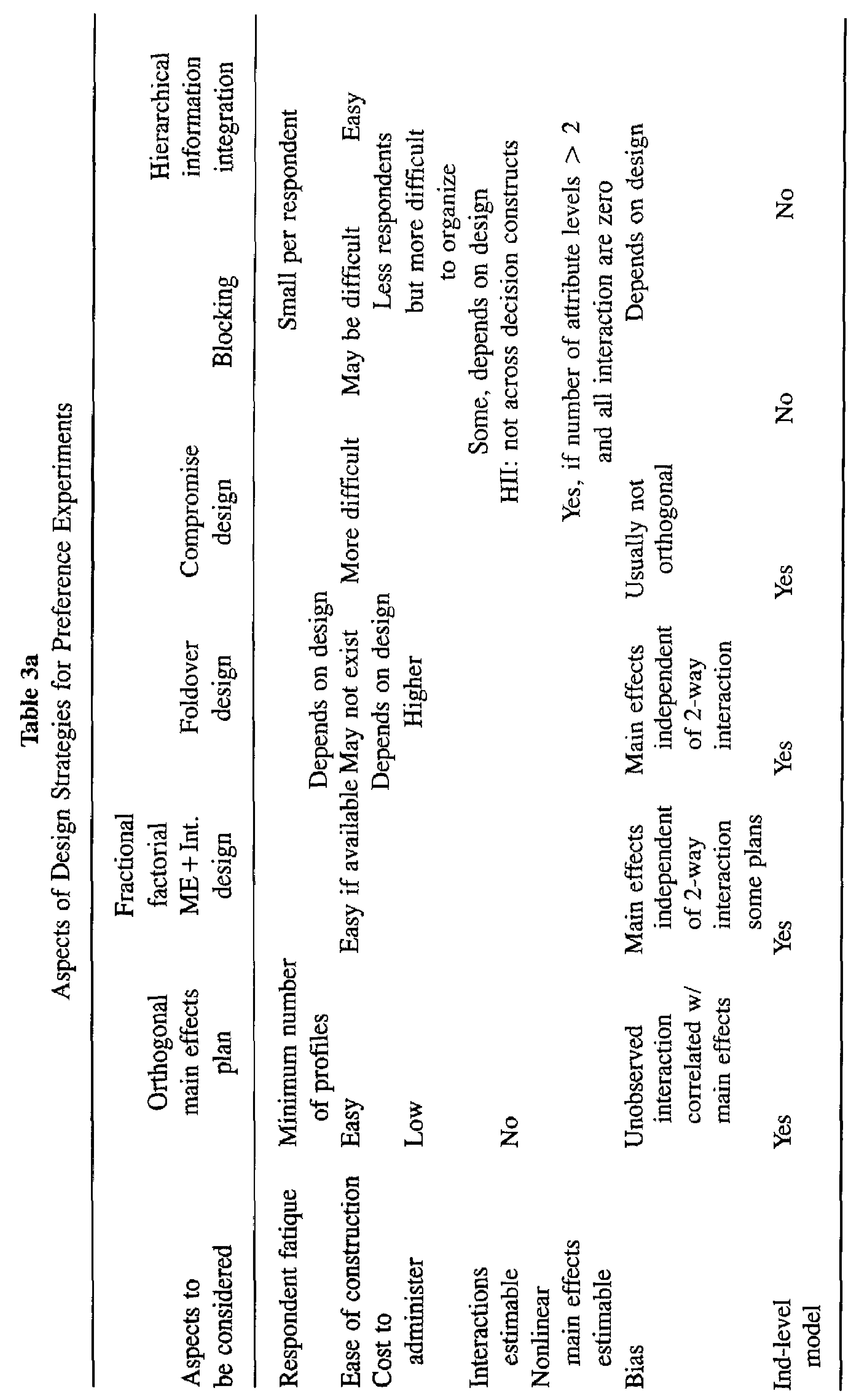


Table 3b

Aspects of Design Strategies for Choice Experiments

\begin{tabular}{|c|c|c|c|c|c|}
\hline & \multicolumn{3}{|c|}{ Paired Comparison Designs } & \multicolumn{2}{|c|}{ Multiple Comparison Designs } \\
\hline & All pairs & Foldover & Randomized & Randomized & Orthogonal plans \\
\hline \multicolumn{6}{|l|}{ Estimable } \\
\hline $\begin{array}{l}\text { interactions } \\
+ \text { nonlinear } \\
\text { main effects }\end{array}$ & \multicolumn{5}{|c|}{ (see Table 3a) } \\
\hline IIA & Testable & $\begin{array}{c}\text { Assumed } \\
\text { true }\end{array}$ & $\begin{array}{l}\text { Assumed } \\
\text { true }\end{array}$ & $\begin{array}{l}\text { Assumed } \\
\text { true }\end{array}$ & Testable \\
\hline \multicolumn{6}{|l|}{ Utility } \\
\hline function & \multirow{2}{*}{\multicolumn{3}{|c|}{$\begin{array}{l}\text { Usually generic } \\
\text { Larger } \rightarrow \text { smaller } \\
\text { decrease }\end{array}$}} & \multirow{2}{*}{\multicolumn{2}{|c|}{$\begin{array}{c}\text { Generic and alternative-specific } \\
\text { Often smaller Often larger } \\
\text { Depends on design }\end{array}$}} \\
\hline $\begin{array}{l}\text { Number of choice } \\
\text { sets }\end{array}$ & & & & & \\
\hline $\begin{array}{l}\text { Statistical } \\
\text { properties }\end{array}$ & $\begin{array}{l}\text { Orthogonal } \\
\text { within } \\
\text { and } \\
\text { between } \\
\text { alts. }\end{array}$ & $\begin{array}{l}\text { Orthogonal } \\
\text { only } \\
\text { between } \\
\text { alts. }\end{array}$ & $\begin{array}{l}\text { Orthogonal } \\
\text { only } \\
\text { within } \\
\text { alts. }\end{array}$ & $\begin{array}{l}\text { Orthogonal } \\
\text { only } \\
\text { within } \\
\text { alts. }\end{array}$ & $\begin{array}{l}\text { Orthogonal } \\
\text { within and } \\
\text { between alts. }\end{array}$ \\
\hline
\end{tabular}

Attribute orthogonality generally will not be retained if one creates choice sets by drawing pairs of profiles at random without replacement from one or more fractional factorial designs and placing these in choice sets. However, this design strategy can satisfy the sufficient conditions for efficient estimation of the parameters of MNL models if one adds a constant, third alternative to each pair. Frequently a third alternative like "I would choose neither of these profiles" is an obvious choice. This third alternative serves as the base of the utility scale, and because its attribute values are constant, it does not change the orthogonality properties of the original profiles. This strategy also can be used to create multiple comparisons by creating $M$ sets of $N$ profiles with identical statistical properties and placing them in $M$ hats. One randomly draws $M$ profiles at a time to create $\mathrm{N}$ sets of $\mathrm{M}$ competing alternatives. This design strategy has the advantage that one can observe more profiles with fewer choice sets by constructing larger choice sets. For example, $\mathrm{M}$ main effects plans describing $\mathrm{N}$ competing options can be aggregated to test many interaction effects. Individuals choose one of the $M$ alternatives or a constant, $M+1$-th alternative ("no choice") added to each choice set to retain attribute orthogonality.

Case 2: IIA Is Satisfied, Alternative Specific Utility Functions. One again must assume that the MNL model is a good approximation to the underlying choice process, but each choice alternative may have different attribute effects. Such problems are often associated with the use of $\mathrm{M}$ real, named choice alternatives such as real parks (e.g., Yosemite, Yellowstone). The design problem is to put $\mathrm{N}$ profiles into choice sets such that separate attribute effects can be estimated for each alternative, if necessary. This can be accomplished by designing the profiles to estimate whatever utility specification one 
desires for each choice alternative, then randomly assigning the profiles into $\mathrm{N}$ choice sets. Because the $M-$ th alternative has a fixed set of $N$ profiles, choice sets that satisfy the necessary conditions to estimate the parameters of MNL models can be created by assigning the $\mathrm{N}$ sets of $\mathrm{M}$ profiles randomly without replacement into choice sets of size $M$ and adding an $\mathrm{M}$-th plus one option as a constant choice to retain attribute orthogonality.

Case 3: IIA-Tests. If one suspects that the IIA property of the MNL models is incorrect, one can test that possibility and develop less restrictive models. For example, IIA is violated if changes in one or more attributes of a particular alternative affect the choices of other alternatives significantly more or less than would be predicted by shifts in utilities: IIA requires the shifts in shares to be proportional to shifts in utility. Choice designs can be constructed to test IIA by estimating the effects of the attributes of each alternative on the choice of other alternatives. To do this efficiently, the attributes of the choices alternatives must be independent not only within but also between alternatives.

The design strategy in this case is to treat each attribute of each alternative as a separate factor, and select an orthogonal main effects plan to vary the attributes of all alternatives simultaneously in an independent manner. For example, if each alternative (M) has $\mathrm{J}$ attributes, each with L levels, one selects orthogonal fractions from the $\mathrm{L}^{(\mathrm{M} \cdot \mathrm{J})}$ factorial. In other cases, one can test whether the presence or absence of alternatives in choice sets violates IIA. This is done by constructing choice sets based on a $2^{\mathrm{M}}$ factorial design, where $M$ is the number of alternatives. Louvière and Woodworth (1983) describe procedures for constructing such designs; Louvière (1986) describes how to estimate cross-effects models; Anderson and Wiley (1989) describe the general design and estimation problem; Batsell and Polking (1985) describe some general models for the problem.

\section{Examples of Typical Recreational Choice Applications}

To illustrate the foregoing theory and methods and the wide variety of problems for which stated preference and choice models may be appropriate, we discuss several typical recreational research applications below.

\section{Problem 1: The Perception/Image of Recreational Alternatives}

Managers of recreational facilities often are interested in the image that individuals have of competing recreational alternatives, the factors that influence these images and the position that particular recreational alternatives occupy in individuals' minds (Ries and Trout 1981). This kind of information is important for marketing and strategy purposes because it may be that a good strategy to increase attendance is to change consumer perceptions or images rather than the physical attributes of the alternatives. Stated preference and choice models, unlike traditional revealed behavior models, can address problems like this.

An example of the use of stated preference models (conjoint analysis models in particular) to analyze recreation problems of this type can be found in Green and de Sarbo (1978). They studied individuals' perceptions of three vacation spots: London, Las Vegas, and Bermuda, with respect to six attributes (food, sightseeing opportunities, outdoor sport opportunities, night life, entertainment, chance to meet new friends, and 
total trip cost). Each attribute was assigned three levels and an orthogonal main effects design involving 18 profiles was developed to produce various hypothetical vacation descriptions. Individuals were asked which of the 18 places they would most desire to visit for a week if they could afford it. Next they were asked to rate each of the 18 profiles on a nine category dissimilar/similar scale relative to the chosen place. Dummy variable regression analysis was used to estimate the relative contribution of each attribute to each individual's overall similarity ratings (relative to the chosen vacation spot). A separate analysis was conducted for each chosen vacation spot, which enables one to examine part-similarity functions, saliences that measure how important each attribute is to the total judged similarity, the nature and extent of misperception, differences in perceptions between subjects, etc.

A slightly different approach is illustrated by Louvière and Johnson (1989), who used "brand-anchored" conjoint analysis to measure and model retail images. In this approach one first decides on a set of existing alternatives (for example, parks A, B, C, $D$, and $E$ ) and attributes that influence the choice among them. Rather than objectively defining levels for these attributes, levels are described with reference to the choice alternatives themselves, using each as an exemplar of the attribute levels (e.g., entrance fee like park A, scenery like park B, etc.). Louvière and Johnson (1989) used an orthogonal main effects plan to create different descriptions (profiles) of alternatives that were described with reference to existing examples. Subjects rated the profile descriptions on a category scale or chose among different pairs, triples, etc., of competing profiles. Response data from this type of task can be analyzed with the same estimation techniques previously discussed. The parameter estimates define the perceptual positions of each alternative on each attribute. Further, these position estimates can be used to predict the probability of choosing alternatives given that they successfully change their perceptual positions.

\section{Problem 2: Preferences for Recreational Management Alternatives}

This is a common applied research problem that illustrates the superiority of stated preference methods to the more traditional approach of asking recreational users to rate or rank recreational alternatives one at a time with respect to sets of attributes (e.g., Timmermans 1987). Recreation managers are often interested in how consumer evaluations, satisfactions, or preferences are likely to change as a function of variations in physical features of recreation facilities. Understanding how choices are influenced by such changes makes it possible to evaluate the likely results produced by a wide array of policy alternatives. Because policymakers often wish to consider alternatives that are radical or new or that involve shifts in attribute values away from levels that have been constant for many years, revealed preference econometric methods may be too restrictive for the analytical needs of decisionmakers. In such instances the power, flexibility, and advantages of stated preference methods are most obvious.

For example, Lieber and Fesenmaier $(1984,1985)$ and Lieber, Fesenmaier, and Bristow (1988) first identified recreational choice attributes that influenced choice of trails in the Chicago area using different techniques described in Allton and Lieber (1983). Exploratory research suggested that five physical features significantly influenced the recreational satisfaction of trail areas: types of trail surface, type of terrain, length of trail, changes between woods and open areas, and proximity to residence. Variations in these attributes in the Chicago area were described by three levels. A fractional factorial design was used to produce 27 trail profiles (descriptions) that were 
combinations of the levels of these attributes. Respondents rated each profile (trail description) on a line mark scale that ranged from "would never use" to "would always use." Various utility functions were estimated from the ratings data, which allowed the authors to estimate the influence of various physical features of recreation facilities on user satisfaction. Once one understands how changes in the attributes affect satisfaction levels, one can predict how possible combinations of actions will impact satisfaction, which permits policymakers to evaluate the likely effects of planning options on user satisfaction.

Lieber and Fesenamier (1984) varied only five attributes. Often, however, managers are interested in the effects of manipulating the levels of many more attributes; or alternatively, consumer satisfaction or preference may be a function of many more attributes. If choice or preferences problems are complex in that they involve many attributes, individuals may simplify such decision processes by using a hierarchically structured (or multistage) information processing strategy. In such cases, the method of Hierarchical Information Integration is a more appropriate research approach than traditional conjoint techniques. For example, Louvière and Timmermans (1989) apply this method to a study in the Eindhoven region of The Netherlands that examined the likely effects on recreational choices of variations in 19 salient attributes of parks and forest preserves. The 19 attributes could be categorized into four sets of decision construct: (1) natural environment and accessibility, (2) facilities and things to do, (3) maintenance, and (4) social use.

These decision constructs were defined in terms of (respectively) five, seven, four, and three attributes. Different fractional factorial designs were developed for each decision construct to vary the levels of the associated attributes. Respondents judged "how good" a park described by a particular combination of attribute levels would be with respect to each decision attribute. That is, individuals rated profiles that described "how good" the natural environment and accessibility (or facilities and things to do, or maintenance and social use, etc.) would be if a hypothetical park had the combination of attribute levels described. Respondents rated each profile on a 0 (very poor natural environment and accessibility) to 10 (very good natural environments and accessibility) category rating scale. In addition to rating sets of profiles that defined each of the four decision constructs, subjects were asked to choose among pairs of parks described by combinations of ratings scores (levels) for the four decision constructs. The rating scores represented the subjects' own ratings of the attribute profiles that defined each decision construct. Individuals chose one park in each of 16 pairs or chose not to go to a park.

The HII approach allows one to estimate separate mappings that define each decision construct to be a function of its respective attributes, and to estimate how changes in the values (expressed as ratings) of the decision constructs influence choices. For example, OLS regression analysis can be used to approximate the way in which each attribute of a particular decision construct influences a subject's definition of how good a park is with respect to that decision construct. Multinomial logit analysis can be used to estimate the parameters of utility functions that describe the way in which subjects' judgements of how good a park is with respect to each decision construct influences their choice of parks. For example, Louvière and Timmermans (1989) concatenated each of the four separate decision construct mappings into the utility specification estimated from the MNL analysis to explain how park choices vary as a function of changes in the levels of all 19 attributes. 


\section{Problem 3: Predicting Recreational Choice Behavior}

Models of recreational choice behavior provide information about the likely effects of managers' actions on use, feasibility of new proposals, etc. Stated preference methods also can be applied to this problem if one can link the predicted preferences for alternatives to overt choice behavior. We know of no applications relating stated preference predictions to actual choices in recreation research, but examples exist in other areas like transportation mode choice (e.g., Louvière and Meyer 1981; Kocur et al. 1982), shopping destination choice, (e.g., Timmermans 1982; Timmermans and van der Heijden 1984; Timmermans et al. 1984) and residential choice (e.g., Louvière and Piccolo 1977; Lermand and Louvière 1979). These and many other studies (e.g., Levin et al. 1983) have demonstrated that preferences predicted by stated preference methods are systematically related to overt choice behavior. Despite these positive empirical results, however, there is no generally accepted way to map predicted preferences into choices. Recently, however, Louvière and Johnson (1989) demonstrate that one can calibrate predicted preferences directly to choices using MNL models. Nonetheless, it is fair to say that all current ways to map stated preference predictions into choices are ad hoc.

Alternatively, choices may be studied directly by using stated (discrete) choice experiments. A typical example is provided by a study of park choice in Johnston County, Iowa by Louviere and Woodworth (1985). They studied the influence of 15 attributes on choice: six attributes had four levels and nine had two levels. An orthogonal, maineffects, fractional factorial design was selected to create two sets of 32 park profiles that varied along the 15 attributes. These 64 park descriptions were placed into 32 choice sets by pairing profiles from the two sets of 32 without replacement in such a way that the rank order correlation between the order of the profiles in the original design sets was minimized. Subjects selected one or the other park or neither. Individual choices were aggregated across choice sets into choice frequencies, which were analyzed by maximum likelihood techniques to estimate the parameters of a multinomial logit model. The model parameters represent the utilities of the attribute levels; hence, one can use the MNL model to forecast how choice probabilities would be likely to change. Louvière and Woodworth (1985) found that distance had the largest effect on park choice, followed by fees, social use, and presence or absence of certain facilities.

\section{Problem 4. Predicting Attendance at Unique Recreational Events}

This problem is a specific case of the previous one, which illustrates how models based on observational data cannot be applied to situations in which data are not available. Stated preference methods apply because they allow one to construct choice alternatives that range over many possible scenarios that might be considered. Louvière and Hensher (1983) and Hensher and Louvière (1984) modeled choices among possible international expositions proposed for Sydney or Melbourne, Australia in conjunction with the Australian bicentennial celebrations in 1988 (plans for Sydney and Melbourne were cancelled; Brisbane later was chosen to host a similar event).

Expos generally involve combinations of five major types of activities: cultural or national exhibits and displays; industrial or technological exhibits and displays; merchandised foods and beverages of different national and ethnic origin; shows and spectacles; and rides, amusements, and games. These five activity categories could be present 
or absent in an expo; and accordingly, each category was treated as a factor in a fraction of the $2^{5}$ factorial. This fractional factorial defined eight expo types according to which activities were present. A $2^{8}$ design was constructed to place the eight expo types into 16 choice sets by treating each expo type as a separate factor whose levels were entrance prices (low or high). Respondents choose to attend one expo in each of the 16 choice sets, or to not attend at all. The estimated model enabled Hensher and Louvière (1984) to decide on optimal expo configurations, pricing policies, consumer surplus, etc.

\section{Problem 5: Predicting Choices in a Competitive Environment}

Frequently, managers are interested in the likely choices that can be attracted to a new recreation facility that would compete with other existing facilities. In addition, it is often important to know what features new alternatives should offer to maximize their market share and/or to minimize cannibalization of certain existing facilities. Problems like this require one to define new choice alternatives in terms of explanatory variables in choice models. To the extent that one can observe choices among existing alternatives that have sufficient variation in attribute levels to permit unconfounded estimates of the attribute effects (and the new alternative does not contain "new" attributer), one can forecast shares of the new alternative as a function of its projected attribute levels. Alternatively, stated choice models offer a more direct approach because choice experiments can be designed to model choices between new and existing choice alternatives.

There are several possible ways to design experiments for this problem. For example, one might use fractional designs to create as many profiles as necessary to estimate the effects of interest for possible new alternatives, and create choice sets that contain profiles that describe new alternatives, together with all existing competitors. This has the advantage that violations of IIA can be tested for the new choice alternative vis-à-vis existing competitors. Alternatively, one can treat each existing competitor as a factor with two levels (present/absent), and create an orthogonal design of the $M$ competitors and the $\mathbf{P}$ attributes of the new alternatives. This design problem, therefore, consists of selecting fractions from the $2^{\mathrm{M}} \mathrm{L}^{\mathrm{P}}$ factorial (assuming all $\mathrm{P}$ attributes have $\mathrm{L}$ levels).

Louvière and Timmermans (1988) illustrate the use of the latter approach in a study of recreational choice behavior in the Eindhoven region, The Netherlands. Nineteen attributes were used to describe new parks. A 32 profile, fractional factorial design was used to vary the levels of these attributes. Eleven existing parks were identified as potential competitors of a new park; and each existing park was treated as a two-level (present/absent) factor. Combinations of competing parks were created by selecting 32 treatments from the $2^{11}$ factorial. Profiles from the two designs (new park attributes versus presence/absence of existing parks) were paired at random to create 32 choice sets. Each choice set contained a description of a new park and a subset of the 11 existing parks; respondents were asked to choose one park from each set. Individuals' choices were aggregated across respondents into choice frequencies, which served as proxies for the unobserved probabilities. The parameters of a utility function were estimated from the choice data by the method of maximum likelihood. The results allow one to draw conclusions about the likely effects of changing the levels of the various new park attributes on individuals' choices, as well as how choices are likely to vary if different parks are unavailable to consumers for whatever reasons. 


\section{Problem 6: Estimating Context Effects}

Empirical research suggests that the effects of a particular attribute may depend on its range of levels. That is, individuals may pay more attention to attributes with larger variances because a small variance among alternatives on a particular attribute encourages one to ignore it in favor of some other, more differentiating attributes. Stated preference methods have been used to examine attribute range effects in apartment and facility choice (Eagle 1984, 1988; Meyer and Eagle 1982) and choice of parks and recreation areas (Curry et al. 1983). This research suggests that the number of levels used for each attribute, the range of levels used for each attribute and the portion of the scale used for the attribute levels modify the effects of park variables. The findings imply that choices may be context-specific, in which case choice models need to incorporate such effects to predict management policy impacts. For example, improvements in certain attributes of parks may have less impact for certain attribute levels, or be different for different attribute ranges of current parks. It is more difficult to design and analyze such effects in discrete choice models, although some specifications of context-sensitive models have recently been developed (e.g., Borgers and Timmermans 1987, 1988).

The applications examples discussed previously are a small sample of the types of problems that can be addressed by stated preference and choice methods. These examples were selected because of relevance to leisure research rather than breadth of exemplars; however, applications in transportation, marketing, and urban planning also demonstrate the usefulness of stated preferences and choice models. Examples of such applications include studies of residential choice (Lerman and Louvière 1979), pricing (Hensher and Louvière 1983; Mahajan, Green, and Goldberg 1982), (place) loyalty/ switching behavior (Hensher and Louvière 1979), variety seeking (McAlister 1979), multipurpose travel (Timmermans 1988a), location-allocation policies (Parker and Srinivasan 1976), product positioning (Louvière 1986), and share changes in competitive markets (Louvière 1984b). In addition to these example applications, we are working on extending stated preference and choice models to problems of joint decision making, spatial choice dynamics, and contextual/situational decision making. Thus, the domain of application for stated preference and choice models is potentially large.

\section{Discussion and Conclusions}

The purpose of this article is to outline conceptual, research design, and analysis issues in the use of stated preference and choice models, and describe some applications in recreation/leisure research. Although we suggest that stated and revealed behavior methods can be complements as well as substitutes, stated behavior methods clearly are preferable to no analysis in situations in which observations of actual behavior are precluded. In general, stated preference models offer several advantages in circumstances in which a lack of statistical controls creates undesirable statistical properties in real data. For example, explanatory variables may be highly collinear, limited in range, or lack variation in or experience with new features or attributes. Of course, no econometric technique, however sophisticated, can be applied to problems in which new alternatives are introduced that possess technologically new or different attributes, or attributes whose variance was previously constant or severely restricted to ranges well outside current contexts. Further, alternatives based on radically new technology or policies pose problems for traditional revealed preference analysis procedures. 
In contrast, stated behavior experiments can be designed to reduce or eliminate interattribute collinearities and span desired attribute variations. Stated preference methods also allow one to estimate and test a wide range of utility specifications. Models estimated from revealed behavior data, on the other hand, are subject to a variety of misspecification problems that can be controlled in stated preference data by suitable choice of design. Of course, revealed behavior data have greater surface external validity because models can be estimated directly from real-world behavior. Choice models developed from laboratory-like experiments need to demonstrate that the utility functions estimated from such data can predict real behavior, or can be transformed to do so. Fortunately, several studies have found significant correlations between the results of preference or choice experiments and real-world behavior (Kocur et al. 1982; Schuler 1979; Benjamin and Sen 1983; Levin et al. 1983).

More important, several studies have compared the predictive abilities of both modeling approaches. For example, in a study of mode choice, Louvière et al. (1981) found that stated and revealed behavior models were equal in predictive ability; Timmermans (1984b) concluded that a stated preference model outpredicted an econometric (multinomial logit) model in the case of shopping choices of respondents in the Maastricht region, The Netherlands. Also, it has been shown that state preference models have good structural reliability (McCullough and Best, 1979) and satisfactory temporal stability and structural consistency properties (Green et al. 1972; Acito 1977; Veldhuisen and Timmermans 19784; Veldhuisen, Thijsen, and Timmermans 1984; Scott and Wright 1976; Malhotra 1982; Carmone et al. 1978). Therefore arguments that revealed behavior models have higher predictive validity may not be necessarily true. Indeed, both approaches share common theoretical underpinnings; they should be complimentary. However, more research is required before more definitive conclusions can be reached.

Transferability of model results over space and time is another important issue in model selection. It is difficult to apply revealed behavior models to problems that involve new choice alternatives that are very different from existing ones because there is little reason to believe that the results can be generalized. As well, the parameters of revealed behavior choice models may partly reflect the unique spatial structure of particular study areas and times rather than more generalizable utilities. Unfortunately, this latter possibly implies that one might wish to question the transferability of many revealed data models. Indeed, several transferability tests of econometric discrete choice models have been conducted with varying degrees of success. (Atherton and Ben-Akiva 1976; Galbraith and Hensher 1982; Talvitie and Kirshner 1978), none of which appear to be wholly satisfactory. There is less experience with the transferability of stated preference models, although van der Heijden and Timmermans (1988) found evidence of excellent geographical transferability in a study of spatial shopping behavior.

From a theoretical perspective, both revealed and stated behavior methods have much in common. Both assume that individuals arrive at some choice or preference by integrating partsworth utilities associated with the attribute levels of choice alternatives according to simple algebraic rules. The main difference is the way data are collected and analyzed; and once more, stated preference models are more flexible: For example, to derive tractable specifications, econometric choice models are based on strong assumptions about homogeneity in tastes and preferences among individuals, simultaneity, errors in variables, utility specifications, correlations among the random components of choice alternatives, etc. Stated preference models are more flexible because one can control for many of these problems that occur with observational data, estimate individual-specific preference and choice models, and test and infer a wide range of 
utility functions. We therefore suggest that leisure researchers consider stated preference methods to be complimentary tools to those traditionally used to analyze recreational perceptions, preferences, and choice behavior.

\section{References}

Acito, F. 1977. An investigation of some data collection issues in conjoint measurement. In Educators' conference proceedings, 82-85. Chicago: American Marketing Association.

Allton, D. J., and S. R. Lieber. 1983. Attributes of Chicago trial areas. Leisure Sciences 5:197-220.

Atherton, T. H., and M. Ben-Akiva. 1976. Transferability and updating of disaggregate travel demand models. Transportation Research Record 610:12-18.

Benjamin, J., and L. Sen. 1983. An empirical test of the utility of attitudinal measures for short-term transportation planning. Final report DOT/RSPA/DMA-50/83/24, U.S. Department of Transportation, Office of University Resecarch. Washington, D.C.: U.S. Government Printing Office.

Borgers, A.W. J., and H. J. P. Timmermans. 1987. Choice model specification, substitution and spatial structure effects: A simulation experiment. Regional Science and Urban Economics $17: 27-49$.

Borgers, A. W. J., and H. J. P. Timmermans. 1988. A context sensitive model of spatial choice behavior. In Behavioural modelling in geography and planning, 159-79. Eds. R. G. Golledge and H. J. P. Timmermans. Beckenham, Kent: Croom Helm.

Bunch, D. S., and R. R. Batsell. 1989. A Monte Carol comparison of estimators for the multinomial logit model. Journal of Marketing Research 26:56-69.

Carmone, F. J., P. E. Green, and A. K. Jain. 1978. Robustness of conjoint analysis: Some Monte Carlo results. Journal of Marketing Research 15:300-303.

Cattin, P., and D. R. Wittink. 1982. Commercial use of conjoint analysis: A survey. Journal of Marketing 46:44-53.

Cattin, P., and D. R. Wittink. 1986. Commercial use of conjoint analysis: An update. Presented at the ORSA/TIMS Marketing Science Meetings, March 12-15, Richardson, TX.

Curry, D. J., J. J. Louviere, D. Rauch, and G. Woodworth. 1983. Recreation destination choice, Institute of Urban and Regional Research, final report 35. Oakdale, IA: The University of Iowa.

Eagle, T. C. 1984. Parameter instability in disaggregate retail choice models: Experimental evidence. Journal of Retailing 60:101-23.

Eagle, T. C. 1988. Context effects in consumer spatial behaviour. In Behavioural modelling in geography and planning, 299-325. Eds. R. G. Golledge and J. J. P. Timmermans. Beckenham, Kent: Croom Helm.

Galbraith, R., and D. Hensher, 1982. Intra-metropolitan transferability of mode-choice models. Journal of Transport Economics and Policy 16:7-29.

Green, P. E., F. J. Carmone, and Y. Wind. 1972. Subjective evaluation models and conjoint measurement. Behavioral Science 17:288-99.

Green, P. E., and W. S. DeSarbo. 1978. Additive decomposition of perceptions data via conjoint analysis. Journal of Consumer Research 5:58-65.

Hensher, D. A., and J. J. Louvière. 1979. Behavioural intentions as predictors of very specific behaviour. Transportation 8:167-82.

Hensher, D. A., and J. J. Louvière. 1983. Individual preferences for international air fares. Journal of Transport Economics and Policy 17:225-45.

Hensher, D. A., and J. J. Louvière, 1984. Towards an approach to forecasting attendance at unique events using a discrete choice model and experimental design data. In Discrete choice models in regional science, 67-87. Ed. D. Pitfield. London: Pion.

Heijden, R. E. C. M. van der, and H. J. P. Timmermans. 1988. The spatial transferability of a stated multi-attribute preference model. Environment and Planning $A$ 20:1013-25.

Knopp, T. B. 1972. Environmental determinants of recreation behavior. Journal of Leisure Research 4:129-1381. 
Kocur, G., W. Hyman, and B. Aunet. 1982. Wisconsin work mode-choice models based on functional measurement and disaggregate behavioral data. Transportation Research Record 895:24-31.

Lerman, S. R., and J. J. Louvière. 1979. Using functional measurement to identify the form of utility functions in travel demand analysis. Transportation Research Record 673:78-86.

Levin, I. P., J. J. Louvière, K. L. Norman, and A. Schepanski. 1983. External validity tests of laboratory studies of information integration. Organizational Behavior and Human Performance 31:173-193.

Lieber, S. R., and D. R. Fesenmaier. 1984. Modelling recreation choice: A case study of management alternatives in Chicago. Regional Studies 18:31-43.

Lieber, S. R., and D. R. Fesenmaier. 1985. Physical and social conditions affecting recreation site preferences. Environment and Planning $A$ 17:1613 27.

Lieber, S. R., D. R. Fesenmaier, and R. S. Bristow. 1988. Social and environmental characteristics affecting alternatives for outdoor recreation participation. In Behavioral modelling approaches in geography and planning. Eds. R. G. Giolledge and H. J. P. Timmermans. London: Croom Helm.

Louvière, J. J. 1984a. Hierarchical information integration: A new method for the design and analysis of complex multiattribute judgment problems. In Advances in consumer research Vol, XI 148-55. Ed. Th. C. Kinnear. Provo, UT: Association for Consumer Research.

Louvière, J. J. 1984b. Using discrete choice experiments and multinomial logit choice models to forecast trial in a competitive retail environment: A fast food restaurant illustration. Journal of Retailing 60:81-107.

Louvière, J. J. 1986. A conjoint model for analyzing new product positions in a differentiated market with price competition. Advances in Consumer Research 13:376-80.

Louvière, J. J. 1988. Analyzing decision making: Metric conjoint analysis. Newbury Park, CA: Sage.

Louvière, J. J. et al. 1981. Laboratory-simulation versus revealed preference methods for estimating travel demand models. Transportation Research Record 794:41-51.

Louvière, J. J., and G. J. Gaeth. 1987. Decomposing the determinants of retail facility choice using the method of hierarchical information integration: A supermarket illustration. Journal of Retailing 63:25-48.

Louvière, J. J., and D. A. Hensher. 1983. On the design and analysis of simulated choice or allocation experiments in travel choice modelling. Transportation Research Record 890:1117.

Louvière, J. J., and R. Meyer. 1981. A composite attitude-behavior model of traveller decision making. Transportation Research 15:411-20.

Louvière, J. J., and R. D. Johnson. 1989. Using conjoint analysis to measure retail image. In New developments in retail location analysis. New York: Lexington Books, forthcoming.

Louvière, J. J., and M. Piccolo. 1977. Information integration theory applied to real-world choice behavior: Validation experiments involving out-of-town shopping and residential choice. Great Plains/Rocky Mountains Geographical Journal 6:5-21 (special issue).

Louvière, J. J., and H. J. P. Timmermans. 1987. A review of some recent advances in stated preference and choice models. Presented at the fifth colloquim on theoretical and quantitative geography. September 8-11, Bardonnecchia, Italy.

Louvière, J. J., and H. J. P. Timmermans. 1988. Park choice behaviour in a competitive environment: A model derived from experimental design data. Forthcoming.

Louvière, J. J., and H. J. P. Timmermans. 1989. Hierarchical information integration applied to recreation destination choice. Environment and Planning A, forthcoming.

Louvière, J. J., and G. Woodworth. 1983. Design and analysis of simulated consumer choice or allocation experiments: An approach based on aggregate data. Journal of Marketing Research 20:350-67.

Louvière, J. J., and G. G. Woodworth. 1985. Models of park choice derived from experimental 
and observational data: A case study in Johnston County, Iowa. Unpublished technical report. University of Iowa, Iowa City, IA.

Luce, R. D. 1959. Individual choice behavior. A theoretical analysis. New York: John Wiley and Sons.

Mahajan, V., P. E, Green, and S. M. Goldberg. 1982. A conjoint model for measuring self- and cross-price/demand relationships. Journal of Marketing Research 19:334-42.

Malhotra, N. 1982. Structural reliability and stability of non-metric conjoint analysis. Journal of Marketing Research 19:199-207.

McAlister, L. 1979. Choosing multiple items from a product class. Journal of Consumer Research 6:223-224.

McCullough, J., and R. Best. 1979. Conjoint measurement: Temporal stability and structural reliability. Journal of Marketing Research 16:26-31.

Meyer, R. J., and T. Eagle. 1982. Context-induced parameter instability in a disaggregate model of store choice. Journal of Marketing Research 19:62-71.

Meyer, R. J., I. Levin and J. J. Louvière, 1978. Functional analysis of mode choice. Transportation Research Record 673:1 7.

Nakanishi, M., and L. G. Cooper. 1974. Parameter estimation for a multiplicative competitive interaction model-least squares approach. Journal of Marketing Research 11:303-11.

Nakanishi, M., and L. G. Cooper. 1982. Simplified estimation procedures for MCI models. Marketing Science 1:314-22.

Parker, B. R., and V. Srinivasan. 1976. A consumer preference approach to the planning of rural primary health care facilities. Operations Research 24:991-1025.

Schuler, H. J. 1979. A disaggregate store-choice model of spatial decision making. The Professional Geographer 31:146-56.

Scott, J. E., and P. Wright. 1976. Modelling an organizational buyer's product evaluation strategy: Validity and procedural considerations. Journal of Marketing Research 13:221-24.

Stynes, D. J., and G. L. Peterson.1986. A review of logit models with implications for modeling recreation choices. Journal of Leisure Research 16:295-310.

Talvitie, A., and D. Kirshner. 1978. Specification, transferability and the effect of data outliers in modelling the choice of mode in urban travel. Transportation 7:311-31.

Theil, H. 1971. Principles of econometrics. New York: John Wiley \& Sons.

Timmermans, H. J. P. 1981. Multiattribute shopping models and ridge regression analysis. Environment and Planning $A$ 13:43-56.

Timmermans, H. J. P. 1982. Consumer choice of shopping centre: An information integration approach. Regional Studies 16:171-82.

Timmermans, H. J. P. 1984a. Decompositional multiattribute preference models in spatial choice analysis. Progress in Human Geography 8:189-221.

Timmermans, H. J. P. 1984b. Discrete choice versus stated multiattribute preference models: A comparative analysis of model performance in the context of spatial shopping behaviour. In Discrete Choice Models in Regional Science, 88-101. Ed. D. E. Pitfield. London: Pion.

Timmermans, H. J. P. 1987. Hybrid and non-hybrid evaluation models for predicting outdoor recreation behavior: A test of predictive ability. Leisure Sciences 9:67-76.

Timmermans, H. J. P. 1988a. Multi-purpose trips and individual choice behaviour: An analysis using experimental design data in Behavorial Modelling in Geography and Planning, R. G. Golldege and H. J. P. Timmermans (Eds.), London: Croom Helm, 356-367.

Timmermans, H. J. P. 1988b. Hierarchical information integration applied to residential choice processes, paper presented at the Annual Meeting of the American Association of Geographers, Phoenix, Arizona.

Timmermans, H. J. P., and R. E. C. M. van der Heijden. 1984. The predictive ability of alternative decision rules in stated multiattribute preference models. Sistemi Urbani 5:89-101.

Timmermans, H. J. P., R. van der Heijden, and H. Westerveld. 1984. Decision making between multiattribute choice alternatives: A model of spatial shopping behaviour using conjoint measurements. Environment and Planning A 16:245-250. 
Veldhuisen, K. J., and H. J. P. Timmermans. 1984. Specification of individual residential utility functions: A comparative analysis of three measurement procedures. Environment and Planning $A$ 16:1573-1582.

Woodworth, G. G., and J. J. Louvière. 1985. Fitting large multinomial logit models using iteratively reweighted least squares. Paper presented to the Annual ORSA/TIMS Marketing Science Meetings in Nashville, TN. 